\title{
SISTEM INFORMASI PENGELOLAAN PENJUALAN APLIKASI PADA PERANCANGAN STARTUP NOTICE DENGAN METODE SCRUM
}

\section{INFORMATION SYSTEM OF APPLICATION SALES MANAGEMENT FOR THE DESIGN OF NOTICE STARTUP USING SCRUM METHODOLOGY}

\author{
${ }^{1}$ Kurnia Kusumandari, ${ }^{2}$ Sony Fajar Surya Gumilang, ${ }^{3}$ Muhammad Azani Hasibuan \\ ${ }^{1,2,3}$ Program Studi Sistem Informasi, Fakultas Rekayasa Industri, Telkom University \\ 'kurnia.kusumandari@student.telkomuniversity.ac.id, ${ }^{2}$ mustonie@telkomuniversity.ac.id, ${ }^{3}$ muhammadazani@telkomuniversity.ac.id
}

\begin{abstract}
Abstrak - Notice merupakan salah satu startup yang baru berdiri dan bergerak dalam bidang penjualan aplikasi/software pendidikan. Aplikasi yang dijual bernama Student Monitoring System. Student Monitoring System merupakan sebuah solusi aplikasi yang membantu sekolah dan orang tua agar lebih mudah dalam melakukan pemantauan terhadap siswa di sekolah. Selain pemantauan, disediakan juga informasi grafik perkembangan prestasi siswa yang dapat membantu orang tua mengarahkan anaknya sesuai dengan minat dan bakat yang dimiliki. Penelitian ini mengenai bagaimana membangun suatu sistem informasi pengelolaan penjualan yang efektif dan solutif bagi perusahaan dan pelanggan. Kerangka kerja pengembangan aplikasi yang digunakan pada penelitian ini adalah metode Scrum. Metode ini dipilih karena mampu menyelesaikan proyek-proyek kompleks dengan pendekatan yang inovatif. Pada sisi pelanggan aplikasi ini dilengkapi dengan fitur transaksi, keluhan/ticketing, kelola arsip transaksi, dan live chatting dengan customer support. Pada sisi perusahaan aplikasi ini dilengkapi dengan fitur laporan pendapatan, laporan transaksi, kelola paket, dan kelola keluhan. Adanya fitur-fitur tersebut mampu menjadi solusi yang tepat bagi penjual dan pembeli dalam berkomunikasi, sehingga dapat meningkatkan penjualan dan menjaga loyalitas pelanggan.
\end{abstract}

Kata kunci: sistem informasi pengelolaan penjualan

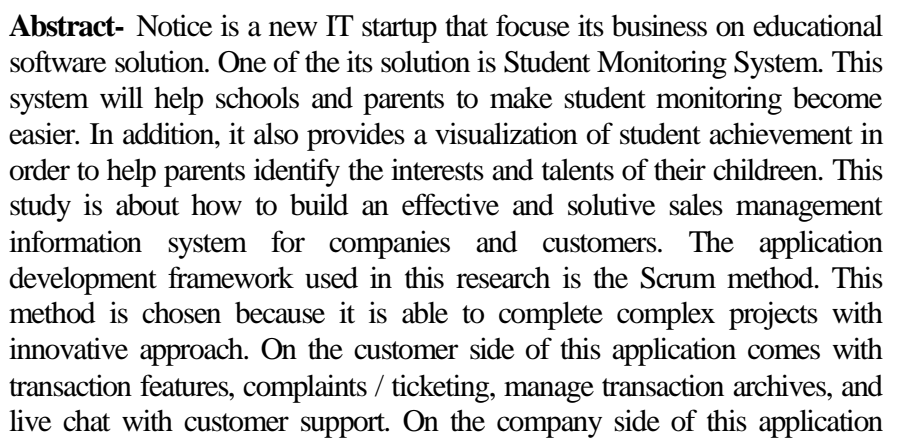

Abstract- Notice is a new IT startup that focuse its business on educational software solution. One of the its solution is Student Monitoring System. This system will help schools and parents to make student monitoring become information system for companes and custion the Scrum method. This transaction features, complaints / ticketing, manage transaction archives, and live chat with customer support. On the company side of this application comes with features of income reports, transaction reports, manage packages, and manage complaints. The existence of these features can be the right solution for sellers and buyers in communicating, so as to increase sales and maintain customer loyalty.

Keywords: Sale management information system

\section{PENDAHULUAN}

Pembangunan perekonomian nasional pada era globalisasi saat ini sangat dipengaruhi oleh kemajuan teknologi. Derasnya perkembangan teknologi menuntut para pelaku bisnis bersaing menjual ide serta gagasan yang dimiliki sekreatif mungkin. Hasil analisis potensi pasar juga memperlihatkan fakta yang sama, yaitu kemampuan untuk mewujudkan kreativitas dengan memadukan nilai seni, pengetahuan, dan juga teknologi dapat menjadi modal besar untuk menghadapi persaingan ekonomi. Salah satu media teknologi yang dapat menunjang para pelaku bisnis untuk menjalankan aktivitasnya ialah media Internet. Internet memungkinkan transaksi secara elektronik (E-commerce) yang dapat mendukung kegiatan pembayaran, komunikasi serta media promosi antara konsumen dengan perusahaan yang memasarkan produk atau jasanya.

Salah satu jenis perusahaan yang erat kaitannya dengan pemanfaatan teknologi yaitu Startup. Saat ini startup seakan menjadi primadona baru dalam industri bisnis di Indonesia. Hampir setiap tahunnya bahkan setiap bulannya berdiri bisnis startup dari berbagai jenis dan kalangan dalam bidang teknologi. Potensi pengguna internet Indonesia yang semakin bertambah dari tahun ketahun tentunya merupakan suatu lahan basah untuk mendirikan startup. Namun dengan banyaknya startup yang berdiri tidak selalu berbanding lurus dengan lama eksistensinya. Hal ini dikarenakan setiap perusahaan startup dituntut untuk selalu melahirkan ide-ide 
kreatif dan eksekusi yang tepat agar dapat menarik hati investor serta pelanggan yang menjadi nafas bagi kelangsungan bisnis startup tersebut. Oleh karena itu, selain ide kreatif startup juga wajib melakukan deliverable product yang baik kepada pelanggannya, contohnya dengan memanfaatkan teknologi informasi dengan baik untuk berkomunikasi dan memasarkan ide serta gagasan kreatifnya.

Notice merupakan salah satu startup yang baru berdiri dan bergerak dalam bidang penjualan aplikasi/software pendidikan. Aplikasi yang dijual bernama Student Monitoring System. Student Monitoring System merupakan sebuah solusi berbasis aplikasi yang membantu sekolah dan orang tua agar lebih mudah dalam melakukan pemantauan terhadap siswa di sekolah. Selain pemantauan, aplikasi ini turut berperan sebagai informasi grafik perkembangan prestasi siswa yang dapat membantu orang tua mengarahkan anaknya sesuai dengan minat dan bakat yang dimiliki.

Konsep yang dibawa oleh Student Monitoring System memang bukanlah suatu ide orisinil, tercatat sudah ada beberapa aplikasi pendahulu yang menghadirkan konsep serupa. Akan tetapi eksistensinya di dunia pendidikan belum memuaskan, bahkan ada beberapa yang dapat dibilang gagal. Hal ini terjadi bukanlah karena faktor cacat aplikasi semata, tetapi karena perusahaan atau pengembangnya tidak memenuhi salah satu unsur dari pengembangan produk atau bisnis tersebut yaitu kebutuhan dan keinginan pasar. Ada dua hal yang pada umumnya melatarbelakangi permasalahan tersebut, yaitu buruknya eksekusi ide tersebut dan keterbatasan dana sekolah sebagai institusi dieksekusinya ide tersebut.

Ide kreatif tanpa diimbangi eksekusi yang baik merupakan suatu hal yang sia-sia. Menilik dari sejarah, banyak startup atau perusahaan yang sukses tidak berangkat dari ide orinisil. Contohnya yaitu Google yang saat ini menjadi website mesin pencari terpopuler nomor satu di dunia, faktanya bukanlah website mesin pencari pertama di dunia. Hal inilah yang terjadi pada aplikasi teknologi pendukung dunia pendidikan yang sudah ada sebelumnya. Mereka hanya menjual produknya tanpa mementingkan feedback apakah aplikasi tersebut cocok dipakai di sekolah atau bagaimana sebenarnya kebutuhan sekolah akan teknologi. Tidak adanya media komunikasi yang tepat juga menjadi alasan mengapa sekolah enggan untuk membeli aplikasi atau hanya sekadar untuk bertanya tentang harga atau penggunaan aplikasi tersebut.

Selain itu keterbatasan dana serta sarana prasarana penunjang penerapan teknologi di sekolah kerap menjadi permasalahan utama. Padahal Undang-Undang Nomor 41 tahun 2008 telah mengamatkan bahwa minimal 20\% APBN/APBD diperuntukkan untuk bidang pendidikan. Namun dalam penerapannya, masih banyak sekolah yang tidak memiliki dana untuk pengadaan aplikasi. Melengkapi hal itu, Kementerian Keuangan menyampaikan bahwa pemerintah telah mengalokasikan anggaran pendidikan sebesar Rp 421,7 triliun atau 20,1\% dari APBN tahun 2016, dan Rp 416,10 triliun atau 20,0\% dari APBN tahun 2017. Tabel I menampilkan rincian anggaran pendidikan tahun 2009-2017.

Hal inilah yang menjadi penyebab utama mengapa sekolah enggan untuk membeli aplikasi dan perangkat teknologi untuk diterapkan di sekolahnya. Harga sebuah lisensi aplikasi absensi berbasis fingerprint contohnya yang dapat mencapai kisaran Rp.5.000.0000 sampai dengan Rp.8.500.000 bukanlah biaya yang murah untuk kategori sekolah non-elite di Indonesia. Belum lagi sekolah harus menyediakan infrastruktur pendukung teknologi tersebut yang bisa dikatakan tidak murah. Berangkat dari permasalahan di atas, maka startup Notice sebagai pelaku bisnis yang bergerak dalam bidang penjualan produk di bidang pendidikan haruslah memenuhi solusi bagi permasalahan tersebut. Untuk mengatasi permasalahan biaya lisensi yang mahal, startup Notice perlu mempertimbangkan kebutuhan fungsional yang diinginkan pelangan lalu disesuaikan dengan kemampuan dana serta sarana prasarana yang berbeda-beda di setiap sekolahnya. Oleh karena itu feedback dari pelanggan sangat dibutuhkan. Startup Notice memerlukan suatu sistem informasi pengelolaan penjualan sebagai bentuk solusi yang mendukung perusahaan dalam mengelola hubungan dengan pelanggan, sehingga pelanggan dapat menyampaikan feedback atau ikut berkontribusi dalam menyampaikan pendapatnya tentang permasalahan yang sering terjadi di sekolah.

TABELI

ANGGARAN PENDIDIKAN TAHUN 2009-2017 [1]

\begin{tabular}{|c|c|c|}
\hline Tahun & $\begin{array}{c}\text { Alokasi } \\
\text { (Rp Triliun) }\end{array}$ & $\begin{array}{c}\text { Rasio } \\
\text { (\% terhadap APBN) }\end{array}$ \\
\hline 2009 & 208,3 & 20,6 \\
\hline 2010 & 225,2 & 20,0 \\
\hline 2011 & 267,0 & 20,2 \\
\hline 2012 & 310,8 & 20,1 \\
\hline 2013 & 345,3 & 20,0 \\
\hline 2014 & 375,5 & 20,0 \\
\hline 2015 & 408,6 & 20,6 \\
\hline 2016 & 421,7 & 20,1 \\
\hline 2017 & 416,10 & 20,0 \\
\hline
\end{tabular}

\section{STUDILITERATUR}

\section{A. Sistem Informasi Pengelolaan Penjualan}

Penjualan merupakan fokus utama setiap usaha di bidang perdagangan. Hasil dari penjualan menentukan berhasil atau tidaknya suatu perusahaan dalam menjalankan usahanya. Dalam kegiatan penjualan diperlukan peran sistem informasi pengelolaan penjualan, dimana sistem informasi penjualan mengalirkan informasi terkait barang atau jasa yang ditawarkan oleh perusahaan pada konsumen dalam bentuk suatu prosedur yang dirancang untuk menghasilkan, menganalisa, menyebarkan dan memperoleh informasi untuk mendukung pengambilan keputusan [2].

Sistem informasi pengelolaan penjualan yang diterapkan dengan teknologi sangat penting untuk meningkatkan kualitas proses bisnis perusahaan, karena penerapan teknologi dapat memaksimalkan kegiatan penjualan. Sistem informasi pengelolaan penjualan bisa diterapkan dalam bentuk teknologi berbasis aplikasi desktop maupun website [3]. Notice merupakan startup yang bergerak dalam bidang penjualan aplikasi/software. Startup Notice menggunakan sistem informasi pengelolaan penjualan berbasis website sebagai penghubung antara perusahaan dengan konsumen. Aktivitas penjualan dapat dilakukan melalui media website diantaranya seperti penerimaan pesanan, penegasan pesanan, pengiriman pesanan, pembuatan faktur, serta laporan operasional penjualan. 


\section{B. Customer Relationship Management}

Customer relationship management atau manajemen hubungan pelanggan merupakan suatu strategi yang digunakan oleh perusahaan dalam menjalin hubungan yang saling menguntungkan dengan pelanggan, sehingga mampu menambah profitabilitas perusahaan berdasarkan kebiasaan pelanggan/customer behavior [4]. Customer Relationship Management (CRM) memberikan kontribusi yang sangat penting terhadap pembentukan brand equity dan brand value suatu perusahaan. Dengan memanfaatkan CRM, perusahaan akan mengetahui apa yang diharapkan dan diperlukan pelanggannya sehingga akan tercipta ikatan emosional yang mampu menciptakan hubungan bisnis yang erat dan terbuka.

Tujuan dari CRM adalah untuk memberikan kepuasan pada pelanggan yang sudah membeli produk atau jasa yang ditawarkan terutama untuk mendapatkan, mempertahankan, dan meningkatkan jumlah pelanggan perusahaan agar tidak beralih pada pesaing. Aktivitas CRM dapat berupa pemantauan produk atau jasa yang sudah dibeli seperti maintenance produk, konsultasi produk, serta pengelolaan data pelanggan. Pada intinya perusahaan bermaksud membangun ikatan yang lebih kuat dengan para pelanggan yang bertujuan untuk memaksimalkan loyalitas pelanggan.

\section{Penelitian Sebelumnya}

Beberapa penelitian terdahulu dikaji pada penelitian ini. Tabel II menampilkan rangkuman dari beberapa penelitian yang sudah dilakukan sebelumnya.

TABEL II

PENELITIAN SEBELUMNYA

\begin{tabular}{|c|c|c|c|c|}
\hline Penulis & $\begin{array}{c}\text { Judul } \\
\text { Penelitian }\end{array}$ & Lokasi Penelitian & Fitur yang Dibangun & Kesimpulan Penelitian \\
\hline $\begin{array}{l}\text { Kristanto, T., } \\
\text { Setyaji, D., \& } \\
\text { Satyawa, P. } \\
\text { (2015). }\end{array}$ & $\begin{array}{l}\text { Analisis } \\
\text { Dan } \\
\text { Perancang } \\
\text { an Sistem } \\
\text { Informasi } \\
\text { Penjualan } \\
\text { Piranti } \\
\text { Multimedi } \\
\text { a Berbasis } \\
\text { Web }\end{array}$ & $\begin{array}{l}\text { Pt Sistem Kreasi } \\
\text { Inovasi Indonesia }\end{array}$ & $\begin{array}{ll}\text { - } & \text { Transaksi pemesanan } \\
\text { - } & \text { History Transaksi } \\
\text { - } & \text { Metode Pembayaran } \\
\text { - } & \text { Kelola Data Pesanan } \\
\text { - } & \text { Laporan Data } \\
& \text { Penjualan }\end{array}$ & $\begin{array}{l}\text { Perlunya penerapan konsep e-commerce pada } \\
\text { penjualan barang atau jasa secara online. } \\
\text { Dalam pemanfaatan e-commerce perlu untuk } \\
\text { menciptakan kehandalan sistem pelayanan agar dapat } \\
\text { membangun kepercayaan pelanggan. }\end{array}$ \\
\hline $\begin{array}{l}\text { Dyantina, O., } \\
\text { Afrina, M., \& } \\
\text { Ibrahim, A. } \\
\text { (2012, } \\
\text { Oktober). }\end{array}$ & $\begin{array}{l}\text { Penerapan } \\
\text { Customer } \\
\text { Relationshi } \\
\text { p } \\
\text { Manageme } \\
\text { nt (CRM) } \\
\text { Berbasis } \\
\text { Web }\end{array}$ & $\begin{array}{l}\text { Sistem Informasi } \\
\text { Pemasaran di } \\
\text { Toko YEN-YEN }\end{array}$ & \begin{tabular}{|ll} 
- & FAQ Pelangga \\
- & Transaksi Pemesanan \\
- & Kelola Data \\
& Pelanggan \\
- & Kelola Data FAQ \\
- & Laporan Penjuala \\
- & Laporan Produk \\
& Terlaris
\end{tabular} & $\begin{array}{l}\text { Hasil penelitian ini adalah sebuah sistem berbasis } \\
\text { web e-CRM yang dapat mengelola data pelanggan, } \\
\text { promosi produk, produk data penjualan, dan } \\
\text { pengelolaan layanan pelanggan yang digunakan } \\
\text { untuk menyimpan pertanyaan pelanggan dan keluhan } \\
\text { pelanggan. }\end{array}$ \\
\hline $\begin{array}{l}\text { Adelia } \quad \& \\
\text { Efdom (2013) }\end{array}$ & $\begin{array}{l}\text { Perancang } \\
\text { an dan } \\
\text { Pembangu } \\
\text { nan Sistem } \\
\text { Informasi } \\
\text { Penjualan } \\
\text { Online }\end{array}$ & Toko Tinta & $\begin{array}{ll}\text { - } & \text { Kelola barang } \\
\text { - } & \text { Kelola berita } \\
\text { - } & \text { Kelola pembayaran } \\
\text { - } & \text { Informasi potongan } \\
& \text { harga }\end{array}$ & $\begin{array}{l}\text { Aplikasi modul penjualan dapat membantu dalam } \\
\text { melakukan transaksi pembelian secara online. }\end{array}$ \\
\hline
\end{tabular}

\section{HASIL DAN ANALISIS}

\section{A. Analisis Kebutuhan Bisnis}

Penelitian ini fokus pada pembuatan aplikasi sistem informasi pengelolaan penjualan dari startup Notice. Penelitian ini diawali dengan melakukan wawancara beberapa calon pengguna. Berdasarkan hasil wawancara yang dilakukan didapatkan informasi bahwa sistem informasi penjualan yang memberikan informasi lengkap terkait harga dan paket yang dijual sangat dibutuhkan oleh pihak sekolah. Pembangunan aplikasi ini juga mengkaji penelitian sebelumnya terkait pentingnya informasi penjualan barang atau jasa.

Hasil dari penelitian menyebutkan bahwa sistem informasi sangat diperlukan dalam sebuah usaha karena dengan sistem informasi, pelanggan akan mudah dalam mendapatkan informasi terkait ketersediaan barang, mudah dalam menyampaikan keluhan, serta mudah dalam melakukan pemesanan. Adanya sistem informasi dapat menjaga loyalitas pelanggan, sehingga pelanggan akan merasa puas karena terlayani dengan baik

Berdasarkan hasil wawancara dan penelitian sebelumnya, kesimpulan yang dapat diambil adalah aplikasi sistem informasi pengelolaan penjualan yang dibangun pada penelitian ini sangat diperlukan oleh startup Notice untuk mendukung proses bisnis perusahaan. Aplikasi tersebut dapat digunakan sebagai media promosi, membantu perusahaan dalam mengelola penjualan dari segi pengelolaan transaksi, barang, dan keluhan pelanggan. Aplikasi tersebut juga dapat membantu pelanggan dalam melakukan transaksi 
pemesanan, melihat informasi harga dan paket, serta penyampaian keluhan

B. Analisis Kebutuhan Teknologi

Berikut merupakan daftar analisa kebutuhan teknologi yang diidentifikasi pada penelitian ini.

TABEL III

ANALISA KEBUTUHAN TEKNOLOGI

\begin{tabular}{|c|c|}
\hline hardware & Spesifikasi \\
\hline Processor & Intel Pentium Dual Core @2.0 Ghz \\
\hline Hard disk & $320 \mathrm{~GB}$ \\
\hline Memory & $1024 \mathrm{MB}$ \\
\hline Monitor & LCD 14” \\
\hline Mouse & - \\
\hline Keyboard & - \\
\hline Printer & - \\
\hline
\end{tabular}

C. Analisis Pengguna

Tabel III menampilkan spesifikasi actor yang diidentifikasi pada penelitian ini.

TABEL 1

SPESIFIKASI AKTOR

\begin{tabular}{|l|l|l|}
\hline No & \multicolumn{1}{|c|}{ Nama Aktor } & \multicolumn{1}{c|}{ Deskripsi } \\
\hline 1 & Super Admin & $\begin{array}{l}\text { Bertanggung jawab untuk } \\
\text { mengelola akun customer dan } \\
\text { akun admin perusahaan }\end{array}$ \\
\hline 2 & Admin Billing Support & $\begin{array}{l}\text { Bertanggung jawab untuk } \\
\text { mengelola data pembayaran, data } \\
\text { keluhan pembayaran, serta } \\
\text { mengelola berita }\end{array}$ \\
\hline 3 & Admin Sales Department & $\begin{array}{l}\text { Bertanggung jawab untuk } \\
\text { mengelola data pesanan, data } \\
\text { paket, data keluhan paket, serta } \\
\text { mengelola berita }\end{array}$ \\
\hline 4 & Customer Terdaftar & Pengguna website my.notice.id \\
\hline 5 & Customer Tidak Terdaftar & Pengunjung website my.notice.id \\
\hline
\end{tabular}

D. Analisis Fungsionalitas Sistem

Dalam tahapan ini, pengembang akan mendefinisikan user story yang akan dibuat dalam use case diagram yang nantinya akan diimplementasi setelah adanya sistem.

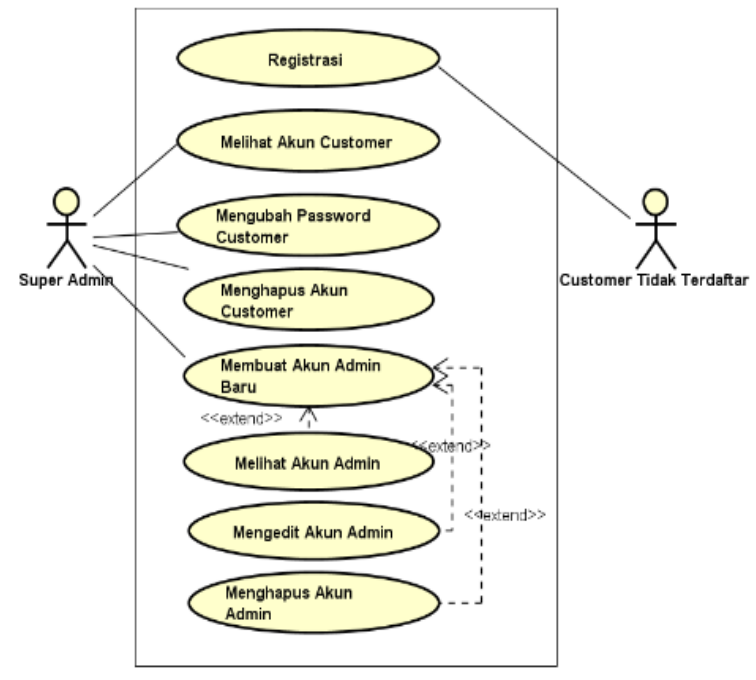

Gambar 1 Use Case Diagram Kelola Akun

ue

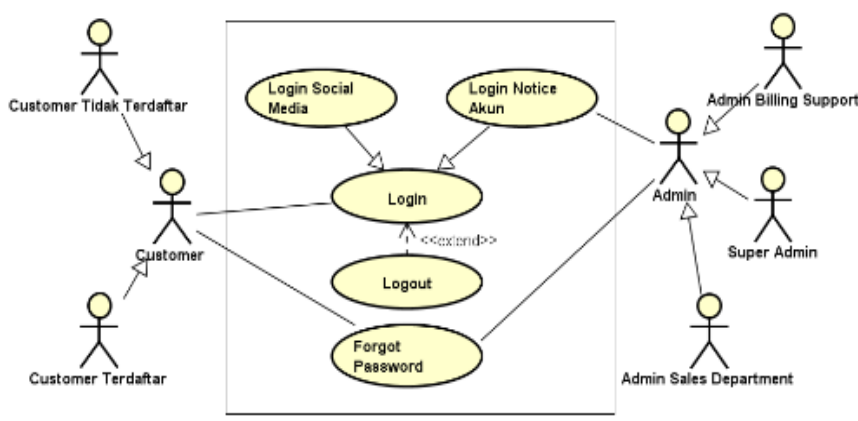

Gambar 2 Use Case Diagram Authentifikasi 
ue J

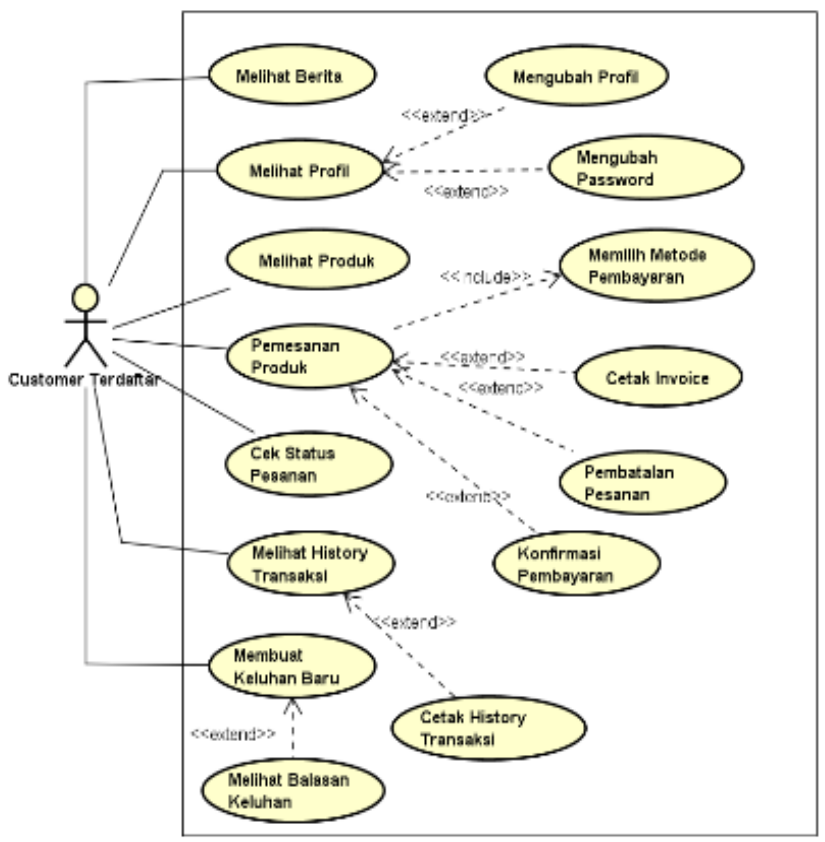

Gambar 1 Use Case Diagram Proses Pemesanan

uc )

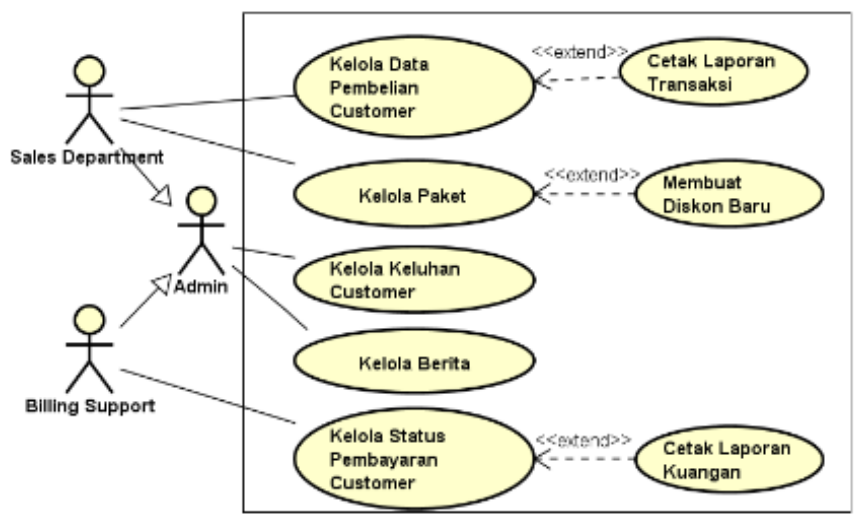

Gambar 2 Use Case Diagram Kelola Data Laporan

E. Proses Bisnis

Proses bisnis merupakan kumpulan aktivitas yang membutuhkan satu atau lebih inputan dan menghasilkan output yang bermanfaat/bernilai bagi pelanggan. Dengan melakukan implementasi sistem informasi pengelolaan penjualan tentunya aktivitas akan berjalan lebih efektif daripada sebelumnya. Gambar 5 menampilkan activity diagram pemesanan produk.

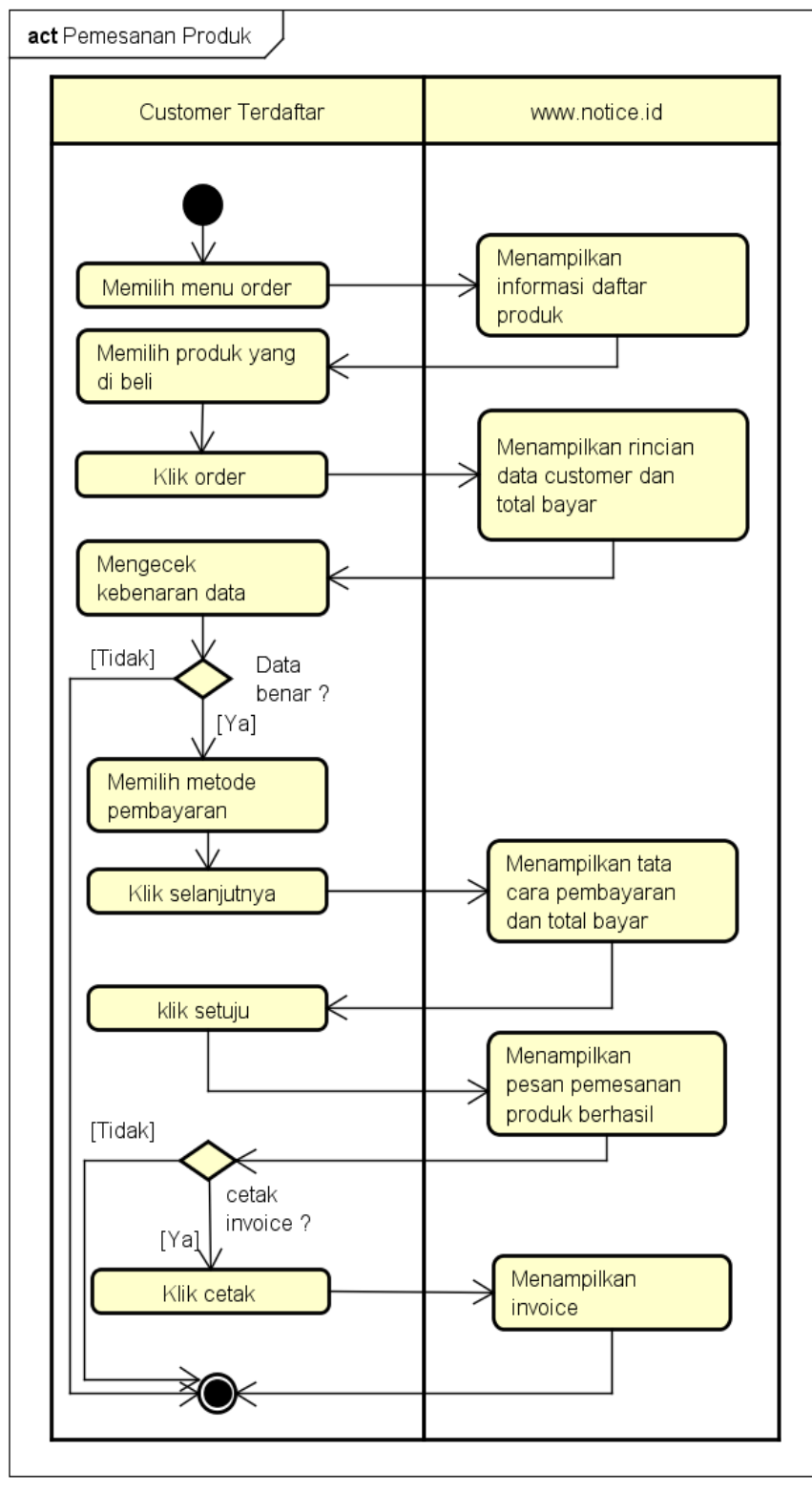

Gambar 5 Activity Diagram Pemesanan Produk

F. Tampilan Program

Gambar 6 sampai Gambar 10 menampilkan hasil interface dari aplikasi sistem informasi pengelolaan penjualan yang berbasis web yang ditujukan untuk startup Notice. Hanya beberapa gambar yang ditampilkan pada artikel ini contohnya, pada Gambar 6 ditampilkan interface untuk halaman Login. Pada Gambar 7 ditampilkan interface untuk halaman dashboard customer, berikutnya Gambar 8 menampilkan halaman kelola akun customer. Pada Gambar 9 ditampilkan halaman history transaksi dan pada Gambar 10 ditampilkan halaman keluhan customer. 


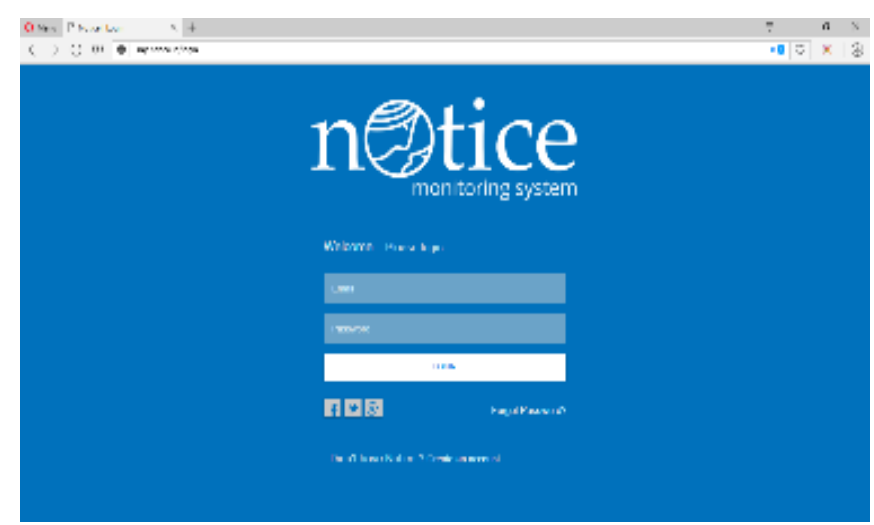

Gambar 6 Halaman Login

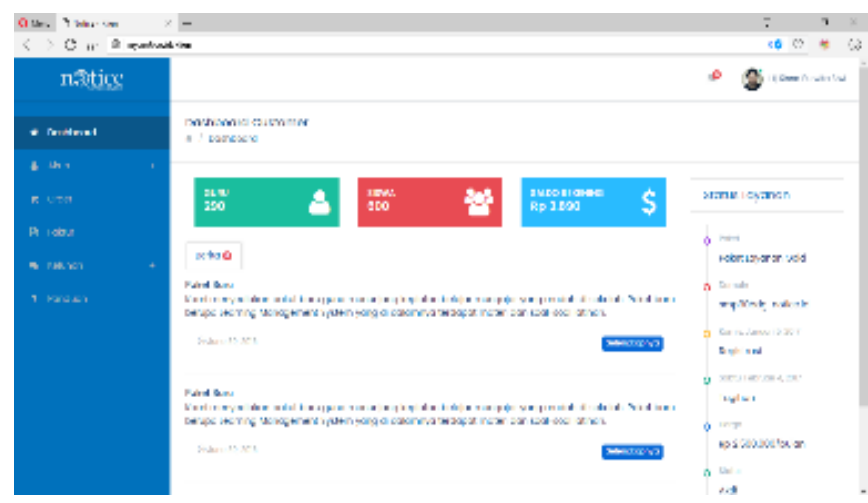

Gambar 7 Halaman Dashboard Customer

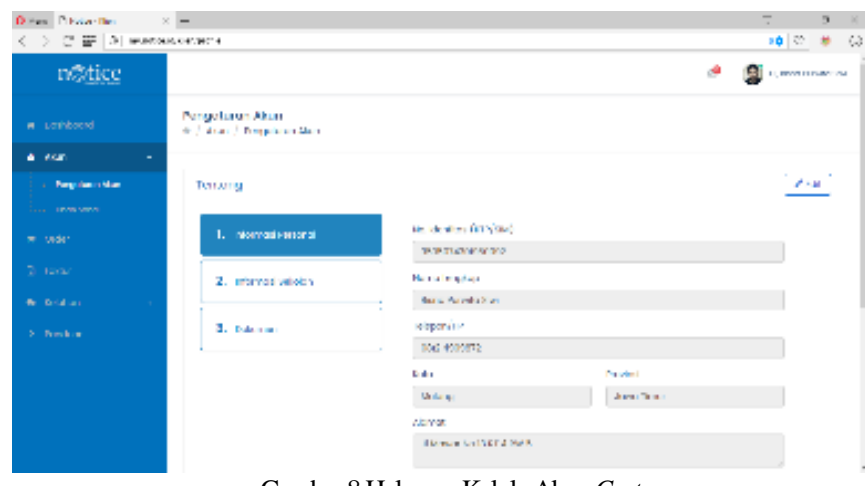

Gambar 8 Halaman Kelola Akun Customer

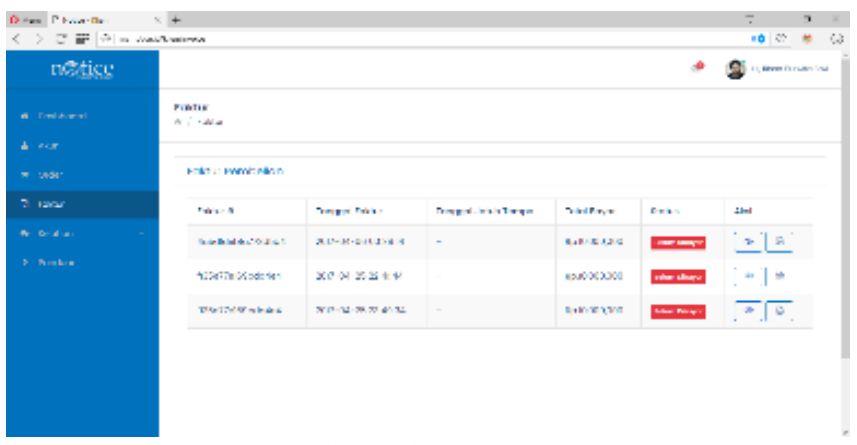

Gambar 9 Halaman History Transaksi

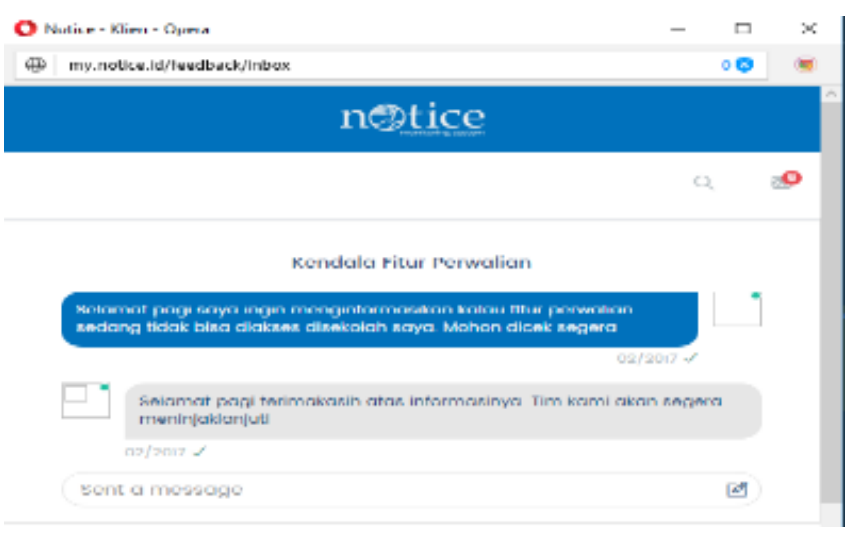

Gambar 10 Halaman Keluhan Customer

\section{PENGUJIAN}

Pengujian yang dilakukan dalam penelitian ini yaitu acceptance testing. Acceptance testing dilakukan di sisi perusahaan dan customer. Berdasarkan skenario pengujian, dilakukan pengujian sistem menggunakan berbagai jenis browser seperti Chrome, Mozilla Firefox, Opera, dan Internet Explorer. Pengujian dilakukan pada semua fungsi sesuai dengan tabel skenario yang diambil atau dibuat dari rancangan use case [5].Tujuan dari pengujian ini adalah untuk memastikan tiap-tiap fungsi telah berjalan dengan baik. Dari pengujian didapatkan hasil yang memuaskan yaitu hampir $100 \%$ dari total keseluruhan fitur yang diuji sukses. Gambar 13 di bawah ini menggambarkan hasil pengujian pada sisi customer. Fungsi yang diuji adalah keseluruhan fitur yang ada pada sisi customer seperti registrasi, transaksi pemesanan, pembuatan keluhan, dan ubah profil. Hasil pengujian menunjukkan bahwa $100 \%$ fitur sukses dijalankan. Gambar 14 di bawah ini menggambarkan hasil pengujian pada sisi supera dmin perusahaan. Fungsi yang diuji adalah keseluruhan fitur yang ada pada sisi superadmin seperti kelola akun customer, kelola akun admin, dan ubah profil. Hasil pengujian cukup memuaskan yaitu $95 \%$ fitur sukses dijalankan.

\section{KESIMPULAN}

1. Sistem informasi pengelolaan penjualan merupakan aplikasi berbasis web yang berfungsi sebagai sistem yang dapat memantau kegiatan penjualan aplikasi pada startup seperti memantau keluhan pelanggan dan melihat total pendapatan.

2. Pentingnya sistem informasi penjualan pada sebuah startup agar customer mudah dalam menemukan informasi seperti informasi ketersediaan aplikasi, paket dan harga yang ditawarkan, serta mudah dalam menyampaikan keluhan.

3. Pentingnya customer relationship management agar dapat menjaga loyalitas customer, sehingga customer puas dan tidak kecewa dengan produk dan kinerja perusahaan.

4. Pentingnya memahami pemodelan bisnis agar dapat mengetahui strategi penjualan aplikasi, khususnya aplikasi yang berbasis software as a service. Aplikasi berbasis SaaS lebih bagus apabila dijual dalam bentuk paket-paket, seperti freemium dan paket gold. Tujuannya adalah agar customer tidak terbebani dengan harga dan bebas memilih modul-modul yang akan dibeli. 


\section{SARAN}

1. Perlu ada perbaikan dalam user interface agar lebih menarik dan lebih mudah digunakan.

2. Perlu dipertimbangkan untuk menambahkan fitur metode pembayaran agar pelanggan tidak melakukan transfer secara manual kepada penjual.

3. Perlu adanya fitur notifikasi pada dashboard pelanggan agar dapat segera mengetahui aktivitas terbaru dalam setiap transaksi yang dilakukan.

Hasil Acceptance Test Customer

$0 \%$

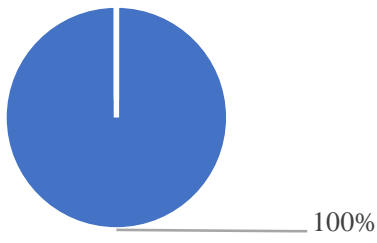

- Sukses - Gagal

Gambar 3 Hasil Pengujian Acceptance Test Customer

Hasil Acceptance Test Super admin

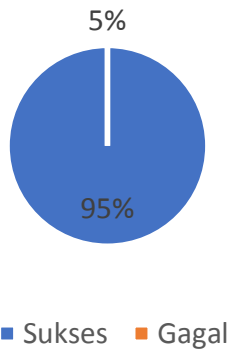

Gambar 4 Hasil Acceptance Test Super admin

\section{DAFTAR PUSTAKA}

[1] RISTEK-DIKTI, Kebijakan Alokasi Anggaran PHLN Kemristekdikti, Kementerian Riset, Teknologi, dan Pendidikan Tinggi, 2017.

[2] T. Kristanto, D. Setyaji and P. Satyawa, "Analisis dan Perancangan Sistem Informasi Penjualan Piranti Multimedia Berbasis Web (Studi Kasus : PT SISTEM KREASI INOVASI INDONESIA)," Seminar Nasional Sains dan Teknologi Terapan III, 2015.

[3] M. Y. Ichwan, Peran Dan Dampak Teknologi di Bidang Pemasaran, Malang: Univeristas Negeri Malang, 2011.

[4] O. Dyantina, M. Afrina and A. Ibrahim, "Penerapan Customer Relationship Management (CRM) Berbasis Web (Studi Kasus Pada Sistem Informasi Pemasaran di Toko YEN-YEN)," Jurnal Sistem Informasi, vol. 4, pp. 516-529, Oktober 2012.

[5] P. Pandit and S. Tahiliani, "AgileUAT: A Framework for User Acceptance Testing," International Journal of Computer Applications, vol. 120 , no. 10, June 2015.

[6] A. Granić and M. Ćukušić, "Usability Testing and Expert Inspections Complemented by Educational Evaluation: A Case Study of an e-Learning Platform," International Forum of Educational Technology \& Society, vol. 2, no. 14, p. 107-123, 2011. 